\title{
Effects of Inhaled Corticosteroids on Pneumonia Severity and Antimicrobial Resistance
}

\author{
Oriol Sibila MD, Elena Laserna MD, Eric M Mortensen MD MSc, \\ Antonio Anzueto MD, and Marcos I Restrepo MD MSc
}

\begin{abstract}
BACKGROUND: Limited information is available regarding the impact of prior use of inhaled corticosteroids (ICS) in patients subsequently developing community-acquired pneumonia (CAP). We assessed the effects of prior ICS use on severity of illness and microbiology in CAP hospitalized patients. METHODS: A retrospective cohort study of subjects with CAP (by the International Classification of Diseases, 9th Revision, Clinical Modification) was conducted over a 4-year period at 2 tertiary teaching hospitals. Subjects were considered to be ICS users if they received ICS prior to admission. Primary outcomes were severity of illness and microbiology at admission. RESULTS: Data were abstracted on 664 subjects: 89 prior ICS users (13.4\%) and 575 non-users $(86.6 \%)$. Prior ICS users had higher severity of illness at admission: mean \pm SD Pneumonia Severity Index $100.8 \pm 31.4$ vs $68.8 \pm 33.4, P=.001$, and CURB-65 (confusion, urea nitrogen, respiratory rate, blood pressure, $\geq 65$ years of age) score $1.56 \pm 1.02$ vs $1.19 \pm 1.02, P=.002$. Prior ICS use was independently associated with antimicrobial-resistant pathogens: $11.2 \%$ vs $5.9 \%$, odds ratio 2.6 , 95\% CI 1.1-6.1, $P=.04$. CONCLUSIONS: Prior ICS use was associated with higher severity of illness at admission and higher incidence of antimicrobial-resistant pathogens in CAP hospitalized patients. Key words: drug resistance; inhaled corticosteroids; pneumonia; severity of illness index. [Respir Care 2013;58(9):1489-1494]
\end{abstract}

\section{Introduction}

Inhaled corticosteroids (ICS) are anti-inflammatory agents widely used in patients with obstructive airways

\footnotetext{
Drs Sibila, Laserna, Anzueto, and Restrepo are affiliated with the University of Texas Health Science Center at San Antonio, San Antonio, Texas. Dr Mortensen is affiliated with the Veterans Affairs North Texas Health Care System and the University of Texas Southwestern Medical Center, San Antonio, Texas. Dr Sibila is also affiliated with Servei de Pneumologia, Hospital de la Santa Creu i Sant Pau, Barcelona, Spain. Dr Laserna is also affiliated with Hospital Comarcal de Mollet, Mollet del Valles, Spain. Drs Anzueto and Restrepo are also affiliated with the South Texas Veterans Health Care System, San Antonio, Texas. Dr Restrepo is also affiliated with the Veterans Evidence Based Research Dissemination and Implementation Center (VERDICT).
}

Dr Anzueto has disclosed a relationship with Boehringer Ingelheim, GlaxoSmithKline, Forest Laboratories, Astra-Zeneca, Pfizer, Intermune, Amgen, Bayer-Schering Pharma, Lilly, and the National Institutes of Health. Dr Restrepo has disclosed relationships with Theravance, Forest Laboratories, Johnson \& Johnson, Trius, Novartis, and Pfizer. This research was supported by Howard Hughes Medical Institute faculty start-up grant 00378-001, and by a Department of Veteran Affairs Veterans Integrated Service Network 17 new faculty grant. Dr Sibila was sup- diseases. Their established efficacy and adequate safety profile have placed these medications in the treatment recommendations for the most prevalent chronic respiratory diseases, such as asthma and COPD. ${ }^{1,2}$

In COPD, the fourth leading cause of death in the United States, ${ }^{3}$ ICS reduce the frequency of exacerbations and improve quality of life. ${ }^{4,5}$ Paradoxically, several large trials

\footnotetext{
ported by Instituto de Salud Carlos III (BAE11/00102). Drs Sibila and Laserna were supported by Sociedad Espanola de Neumologia y Cirugia Toracica (SEPAR), Societat Catalana de Pneumologia and Fundacio Catalana de Pneumologia. Dr Restrepo was partly supported grant K23HL096054 from the National Heart, Lung, and Blood Institute. The funding agencies had no role in the preparation, review, or approval of the manuscript. The views expressed in this report are those of the authors and do not represent the views of the Department of Veterans Affairs.
}

Correspondence: Marcos I Restrepo MD MSc, South Texas Veterans Health Care System ALMD-7400, Merton Minter Boulevard, San Antonio TX 78229. E-mail: restrepom@uthscsa.edu.

DOI: $10.4187 /$ respcare.02191 
have demonstrated that ICS are associated with an increased incidence of community-acquired pneumonia (CAP) in these patients. ${ }^{6-12}$ There is controversy regarding the association between poor clinical outcomes in CAP patients and prior use of ICS.9,13-15 Although recent and numerous randomized trials and meta-analyses have evaluated the impact of ICS on pneumonia-related or overall mortality, ${ }^{6-15}$ few data are available regarding the association of prior ICS with the severity of illness at admission or its impact on antimicrobial resistance. Although chronic systemic corticosteroids use has been associated with higher risk of opportunistic infections ${ }^{16-18}$ and potentially highly drug-resistant pathogens, ${ }^{19,20}$ these associations are not clear in patients treated with ICS. Therefore, our aim was to investigate the association of prior out-patient ICS use with severity of illness and antimicrobial resistance in hospitalized patients with CAP at the time of admission.

\section{Methods}

This was a cross-sectional study of patients hospitalized with CAP at 2 academic teaching tertiary care hospitals in San Antonio, Texas. The institutional review board of the University Health Science Center at San Antonio approved the research protocol, with exempt status.

\section{Inclusion and Exclusion Criteria}

We identified all patients admitted to the study hospitals between January 1, 1999, and December 31, 2002, who had a primary discharge diagnosis of pneumonia (International Classification of Diseases, 9th Revision, Clinical Modification codes 480.0-483.99 or 485-487.0) or a secondary discharge diagnosis of pneumonia with a primary diagnosis of respiratory failure (518.81) or sepsis (038.xx). Subjects were included if they were $>18$ years of age, had an admission diagnosis of CAP, and had a radiographically confirmed infiltrate or other finding consistent with pneumonia on chest X-ray or CT obtained within 24 hours of admission.

Exclusion criteria included having been discharged from an acute care facility within 14 days of admission, transfer after being admitted to another acute care hospital, being on comfort measures only on this admission, and using systemic corticosteroids. If a subject was admitted more than once during the study period, only the first hospitalization was abstracted

\section{Data Abstraction}

Chart review data included: demographics, comorbidities, physical examination findings, laboratory data, chest radiographic reports, guideline-concordant empirical antibiotic therapy, and prior antibiotic use. Comorbidities were

\section{QUICK LOOK}

\section{Current knowledge}

Inhaled corticosteroids are anti-inflammatories that are widely used by patients with COPD. Limited information is available on the impact of prior use of inhaled corticosteroids in patients with community-acquired pneumonia.

\section{What this paper contributes to our knowledge}

Prior use of inhaled corticosteroids was associated with higher severity of illness and incidence of antibioticresistant pathogens in patients admitted with communityacquired pneumonia.

identified from either the admission or discharge notes or out-patient problem lists. Antimicrobial therapy was considered guideline-concordant if it agreed with the American Thoracic Society guidelines. ${ }^{21}$ Prior antibiotic use was defined as having taken any kind of antibiotic $\leq 15$ days before admission. Information on all ICS out-patient medications that were either reported as currently being taken by the subject at presentation or listed in the electronic medical record was recorded. ICS therapy was defined as receiving inhaled beclomethasone dipropionate, triamcinolone, budesonide, or fluticasone propionate at the time of admission.

\section{Diagnostic Criteria}

Microbiologic data results were reviewed, and a microbiologic cause was assigned independently by 2 of the investigators (EMM and MIR). The cause of pneumonia was considered if one of the following conditions were met: blood cultures were positive for bacterial or fungal pathogens (in the absence of an extra-pulmonary source of infection); pleural fluid cultures yielded a bacterial pathogen; endotracheal suctioning samples showed moderate or heavy growth of bacterial pathogens; there was substantial quantitative culture growth from bronchoscopic samples (protected specimen brush culture had $\geq 10^{3}$ colonyforming units $/ \mathrm{mL}$, or bronchoalveolar lavage fluid had $\geq 10^{4}$ colony-forming units $/ \mathrm{mL}$ ). When 2 or more microbiologic causes were present, the subject was considered to have a polymicrobial infection. A subject was considered to have CAP of unknown cause if microbiologic studies were not performed or inconclusive.

Drug-resistant pathogens were defined as drug-resistant Streptococcus pneumoniae, methicillin-resistant Staphylococcus aureus, Acinetobacter baumannii, extended-spectrum beta lactamases, and multidrug-resistant Pseudomonas aeruginosa (resistance to $\geq 3$ antimicrobial categories). ${ }^{22}$ 
Table 1. Subject Demographic and Clinical Characteristics by Use of Inhaled Corticosteroids

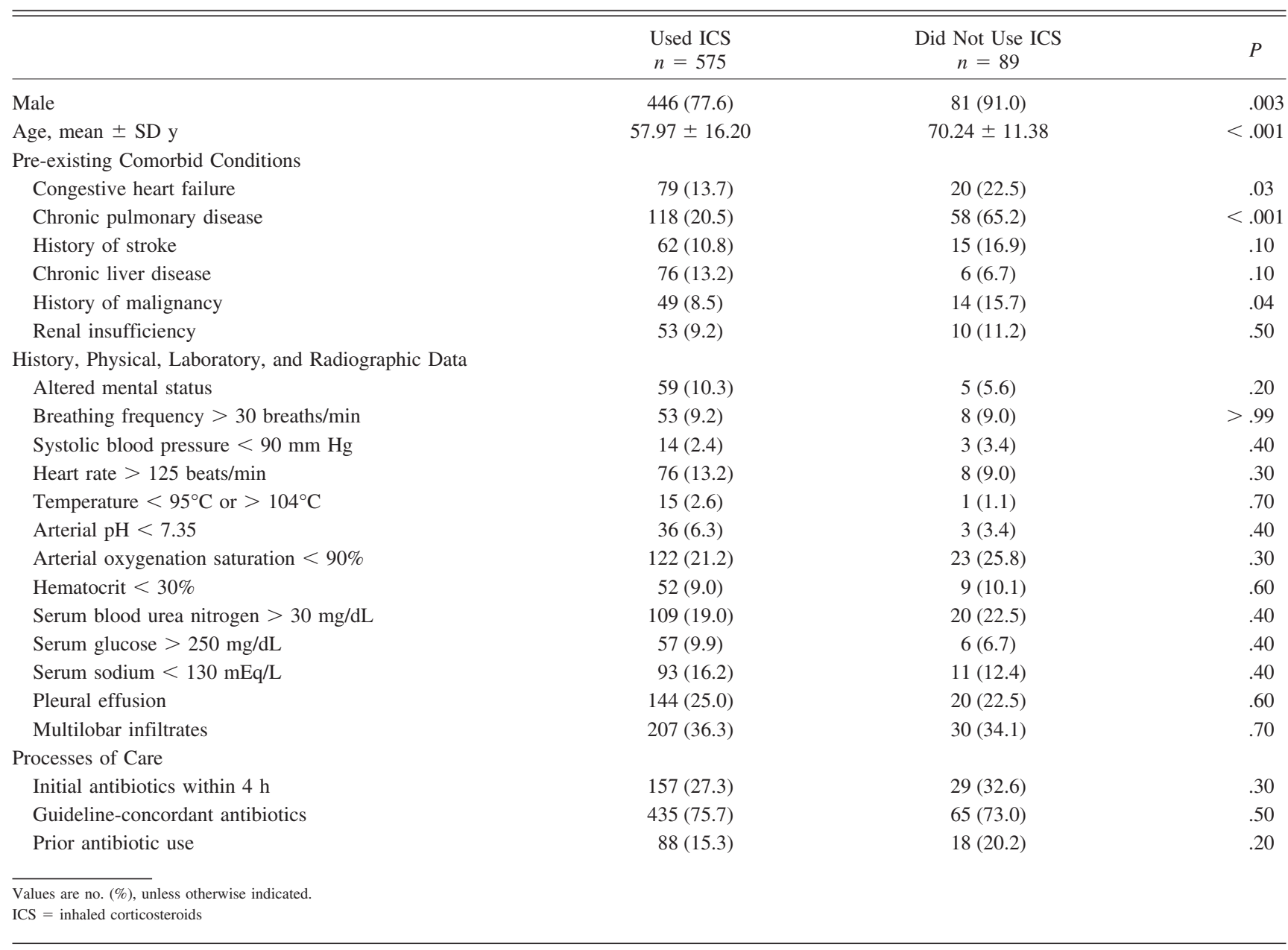

\section{Clinical Outcomes}

The primary outcomes were severity of illness at presentation, defined by the Pneumonia Severity $\operatorname{Index}^{23}$ and CURB-65 (confusion, urea nitrogen, respiratory rate, blood pressure, $\geq 65$ years of age), ${ }^{24}$ and presence of resistant or opportunistic pathogens.

\section{Statistical Analyses}

For the statistical analyses, subjects were stratified according to prior ICS use. Categorical variables were analyzed using the chi-square test, and continuous variables were analyzed using the Student $t$ test. Multivariable analysis was performed using a logistic regression model, with drug-resistant pathogens as the dependent variable, and those with $P<.10$ as independent variables (age, sex, COPD, congestive heart failure, and history of malignancy). Logistic regression results are reported as odds ratio and $95 \%$ CI. Subgroup analyses were performed for sub- jects with and without COPD according to the primary outcomes. COPD represents one the largest groups of ICS users among elderly subjects, and it is the cohort where substantial interest related to complications with ICS has emerged. ${ }^{25}$ Two-sided $P$ values $<.05$ were considered statistically significant. All analyses were performed using statistics software (SPSS 19.0, SPSS, Chicago, Illinois).

\section{Results}

We identified 664 patients who met the inclusion criteria, $89(13.4 \%)$ of whom had received ICS prior to admission, and 575 (86.6\%) had not.

\section{Subject Characteristics}

Subject characteristics are shown in Table 1. Prior ICS users were older, more likely to be male, and had more preexisting comorbidities, such as congestive heart failure, 
Table 2. Etiologies in Patients With Community-Acquired Pneumonia

\begin{tabular}{|c|c|c|c|}
\hline & $\begin{array}{l}\text { Used } \\
\text { ICS } \\
n=575\end{array}$ & $\begin{array}{l}\text { Did Not } \\
\text { Use ICS } \\
n=89\end{array}$ & $P$ \\
\hline Streptococcus pneumoniae & $49(8.5)$ & $8(9.0)$ & .80 \\
\hline Drug-resistant S. pneumoniae* & $27(4.7)$ & $6(6.7)$ & .40 \\
\hline Other Streptococcus & $3(0.5)$ & 0 & $>.99$ \\
\hline Staphylococcus aureus & $29(5.0)$ & $5(5.6)$ & .70 \\
\hline Methicillin-resistant S. aureus & $6(1.0)$ & $3(3.4)$ & .10 \\
\hline Pseudomonas aeruginosa & $11(1.9)$ & $3(3.4)$ & .40 \\
\hline Multi-drug-resistant $P$. aeruginosa $\dagger$ & $1(0.2)$ & 0 & .80 \\
\hline Haemophilus influenzae & $13(2.3)$ & $4(4.5)$ & .20 \\
\hline Escherichia coli & $7(1.2)$ & $1(1.1)$ & $>.99$ \\
\hline Klebsiella pneumoniae & $7(1.2)$ & 0 & $>.99$ \\
\hline Proteus mirabilis & $3(0.5)$ & 0 & $>.99$ \\
\hline Acinetobacter baumannii & 0 & $1(1.1)$ & .10 \\
\hline Aspergillus species & $4(0.7)$ & 0 & $>.99$ \\
\hline Polymicrobial & $8(1.4)$ & $3(3.4)$ & .10 \\
\hline Total pathogens isolated & $135(23.5)$ & $26(29.2)$ & .20 \\
\hline \multicolumn{4}{|c|}{$\begin{array}{l}\text { Values are no. (\%). } \\
\text { * Resistant to cephalosporins, penicillins, macrolides, or fluoroquinolones. } \\
\dagger \text { Resistant to } \geq 3 \text { antimicrobial categories. }{ }^{22}\end{array}$} \\
\hline
\end{tabular}

history of malignancy, or COPD. No significant differences were found between the groups regarding physical exam, laboratory and radiological data, or processes of care.

\section{Microbiological Findings}

An etiologic diagnosis was found in 161 (24.2\%) of hospitalized CAP subjects (Table 2). The prior ICS users and non-users had similar rates of isolated pathogens, including $S$. pneumoniae, $S$. aureus and $P$. aeruginosa. Opportunistic pathogens, such as Aspergillus species, Pneumocystis jiroveci, and Nocardia species and extendedspectrum beta lactamases pathogens, were not found in the ICS users.

\section{Clinical Outcomes}

The subjects who had used ICS had higher mean Pneumonia Severity Index (100.8 \pm 31.4 vs $68.8 \pm 33.4$, $P=.001)$ and CURB-65 scores ( $1.56 \pm 1.02$ vs $1.19 \pm 1.02$, $P=.002)$ at presentation. In the multivariate analyses, after adjusting for potential confounders, the use of outpatient ICS was independently associated with drugresistant pathogens: $11.2 \%$ vs $5.9 \%$, odds ratio $2.6,95 \% \mathrm{CI}$ $1.1-6.1, P=.04$.

\section{Subgroup Analyses}

The COPD subjects who had used out-patient ICS ( $n=58 / 176,33.0 \%$ ) were more likely to have drug- resistant pathogens $(12.1 \%$ vs $3.4 \%$, odds ratio $3.9,95 \% \mathrm{CI}$ 1.1-13.2, $P=.03$ ) than were the COPD subjects without prior ICS use $(n=118 / 176,67.0 \%)$. However, the COPD subjects with prior ICS use had no significant differences regarding severity of illness at presentation: mean Pneumonia Severity Index $103.1 \pm 30.0$ vs $100.7 \pm 30.8$, $P=.6$; mean CURB-65 score $1.6 \pm 0.9$ vs $1.6 \pm 1.1$, $P=.90$, compared to the COPD subjects with no prior ICS use.

The non-COPD subjects managed with ICS ( $n=31$ / $488,6.4 \%)$ were not associated with drug-resistant pathogens $(9.7 \%$ vs $6.6 \%, P=.40)$. However, the non-COPD subjects had higher Pneumonia Severity Index (96.5 \pm 33.97 vs $83.2 \pm 33.2, P=.04)$ than the non-COPD subjects without prior ICS use $(n=457 / 488,93.6 \%)$.

\section{Discussion}

In hospitalized CAP subjects, prior out-patient use of ICS was associated with a higher severity of illness at admission and higher incidence of antimicrobial-resistant pathogens. The relationship between ICS and pneumonia is one of the most important unresolved questions since Calverley et al ${ }^{6}$ reported in 2007 the results of the TORCH (Toward a Revolution in COPD Health) study. Multiple studies have confirmed that COPD subjects treated with ICS have an increased likelihood of developing pneumonia. ${ }^{7-12}$ However, COPD subjects receiving ICS and treated for pneumonia may or may not have worse outcomes, such as higher mortality, compared with subjects not receiving ICS.6-15 This observation has led to speculation that ICS use may increase CAP risk, but, because of ICS immunomodulatory effects, these patients may be protected against severe pneumonia or pneumonia-related complications. ${ }^{26,27}$ Our results suggest that prior ICS users who develop pneumonia and require hospitalization have more severe CAP than ICS non-users (higher Pneumonia Severity Index ${ }^{23}$ and CURB-65 ${ }^{24}$ scores at admission). These results are hypothesis-generating, and require further exploration with larger databases and adjusting for other possible confounding variables. In a study on ICS and pneumonia severity, Singanayaman et $\mathrm{al}^{14}$ found no differences in illness severity at admission in their cohort of COPD patients admitted with pneumonia. These findings are consistent with our subgroup analysis of COPD patients. These data suggest that chronic prior ICS use may play an important role in the lungs' defense mechanisms against infections. We hypothesized that, in addition to the immunomodulatory effects observed in patients treated with ICS, there is the possibility that an immunosuppressive effect might be the cause of the higher disease severity. The immunomodulatory effect may be different between COPD and non-COPD patients. However, further studies are needed to assess the effect of ICS on different 
airway protective mechanisms against infections, such as local inflammatory response, mucins, and antimicrobial peptides, and between different patient populations. ${ }^{28}$

Different studies have identified a higher incidence of potentially highly resistant bacteria ${ }^{19,20}$ and opportunistic lung pathogens such as Aspergillus, ${ }^{17}$ Pneumocystis jiroveci, ${ }^{18}$ and Nocardia, ${ }^{29}$ in patients taking systemic corticosteroids. However, the association of antimicrobialresistant bacteria with out-patient ICS use was unknown. Our study results suggest that patients with prior ICS use admitted to the hospital with CAP, particularly COPD patients, are more likely to have drug-resistant pathogens. Liapikou et $\mathrm{al}^{30}$ reported that COPD patients treated with chronic ICS had a higher rate of pneumonia due to P. aeruginosa, but fewer Legionella species. However, antimicrobial resistance was not assessed in COPD patients treated with ICS.

We hypothesized that ICS may alter habitual flora and antimicrobial susceptibility, particularly in COPD patients with chronic airway infections. ${ }^{31}$ Previous antimicrobial courses have been associated with development of multidrug-resistant pathogens ${ }^{32}$; this is an important variable to consider in future assessment of the risk of antimicrobial resistance related to the use of ICS.

Our study has several limitations. First, this was a retrospective study involving only 2 centers, with a relatively small simple size. Second, our sample was predominately male, due to the higher population of veterans enrolled in this cohort. It is unknown if prior ICS use in females would have similar results. Third, our cohort did not have information regarding the exact ICS dose, ICS clinical indications, or duration of ICS out-patient therapy. Fourth, our database did not include data on multiple courses of antibiotic prescriptions unrelated to the pneumonia hospitalization event. Finally, diagnosis of COPD was not based on spirometry.

\section{Conclusions}

Hospitalized CAP patients receiving prior ICS had a higher severity of disease at presentation and more frequently had antimicrobial-resistant pathogens. Further studies are needed to study mechanisms involved in these important findings, which may affect the current indications of the ICS.

\section{REFERENCES}

1. Global Initiative for Asthma (GINA). The global strategy for asthma management and prevention. Updated December 2011. http://www. ginasthma.org/GINA-Report\%2C-Global-Strategy-for-AsthmaManagement-and-Prevention. Accessed June 21, 2013.

2. Global Initiative for Chronic Obstructive Lung Disease (GOLD). The global strategy for the diagnosis, management and prevention of
COPD, 2011. http://www.goldcopd.org/Guidelines/guidelinesresources.html. Accessed June 21, 2013.

3. Mannino DM, Homa DM, Akinbami LJ, Ford ES, Redd SC. Chronic obstructive pulmonary disease surveillance: United States, 19712000. MMWR Surveill Summ 2002;51(6):1-16.

4. Calverley P, Pauwel R, Vestbo J, Jones P, Pride N, Gulsik A, et al. Combined salmeterol and fluticasone in the treatment of chronic obstructive pulmonary disease: a randomized controlled trial. Lancet 2003;361(9356):449-456. Erratum in: Lancet 2003;361(9369): 1660.

5. Nannini LJ, Cates CJ, Lasserson TJ, Poole P. Combined corticosteroid and long-acting beta-agonist in one inhaler versus placebo for chronic obstructive pulmonary disease. Cochrane Database Syst Rev 2007;(4):CD003794.

6. Calverley PMA, Anderson JA, Celli B; TORCH Investigators. Salmeterol and fluticasone propionate and survival in chronic obstructive pulmonary disease. N Engl J Med 2007;356(8):775-789.

7. Kardos P, Wencker M, Glaab T, Vogelmeier C. Impact of salmeterol/ fluticasone propionate versus salmeterol on exacerbations in severe chronic obstructive pulmonary disease. Am J Respir Crit Care Med 2007;175(2):144-149.

8. Wedzicha JA, Calverley PMA, Seemungal TA, Hagan G, Ansari Z, Stockley RA; INSPIRE Investigators. The prevention of chronic obstructive pulmonary disease exacerbations by salmeterol/fluticasone propionate or tiotropium bromide. Am J Respir Crit Care Med 2008; 177(1):19-26.

9. Ernst P, Gonzalez AV, Brassard P, Suissa S. Inhaled corticosteroid use in chronic obstructive pulmonary disease and the risk of hospitalization for pneumonia. Am J Respir Crit Care Med 2007;176(2): 162-166.

10. Drummond MB, Dasenbrook EC, Pitz MW, Murphy DJ, Fan E. Inhaled corticosteroids in patients with stable chronic obstructive pulmonary disease: a systematic review and meta-analysis. JAMA 2008;300(20):2407-2416.

11. Singh S, Amin AV, Loke YK. Long-term use of inhaled corticosteroids and the risk of pneumonia in chronic obstructive pulmonary disease: a meta-analysis. Arch Intern Med 2009;169(3):219-229.

12. Singh S, Loke YK. Risk of pneumonia associated with long-term use of inhaled corticosteroids in COPD: A critical review and update. Curr Opin Pulm Med 2010;16(2):118-122.

13. Malo de Molina R, Mortensen EM, Restrepo MI, Copeland LA, Pugh MJ, Anzueto a. Inhaled corticosteroid use is associated with lower mortality for subjects with COPD and hospitalized with pneumonia. Eur Respir J 2010;36(4):751-757.

14. Singanayaman A, Chalmers JD, Akram AR, Hill AT. Impact of inhaled corticosteroid use on outcome in COPD patients admitted with pneumonia. Eur Respir J 2011;38(1):36-41.

15. Chen D, Restrepo MI, Fine MJ, Pugh MJ, Anzueto A, Metersky ML et al. Observational study of inhaled corticosteroids on outcomes for COPD patients with pneumonia. Am J Respir Crit Care Med 2011; 184(3):312-316.

16. Stuck AE, Minder CE, Frey FJ. Risk of infectious complications in patients taking glucocorticoids. Rev Infect Dis 1989;11(6):954-963.

17. Conesa D, Rello J, Vallés J, Mariscal D, Ferreres JC. Invasive aspergillosis: a life-threatening complication of short-term steroid treatment. Ann Pharmacother 1995;29(12):1235-1237.

18. Maskell Na, Waine DJ, Lindley A, Pepperell JC, Wakefield AE, Miller RF, Davies RJ. Asymptomatic carriage of Pneumocystis jiroveci in subjects undergoing bronchoscopy: a prospective study. Thorax 2003;58(7):594-597.

19. Falguera M, Carratalà J, Ruiz-Gonzalez, Garcia-Vidal C, Gazquez I, Dorca J, et al. Risk factors and outcome of community-acquired pneumonia due to Gram-negative bacilli. Respirology 2009;14(1): 105-111. 


\section{Effects of Inhaled Corticosteroids on Pneumonia Severity and Antimicrobial Resistance}

20. Sousa D, Justo I, Dominguez A, Manzur A, Izquierdo C, Ruiz L, et al. Community-acquired pneumonia in immunocompromised older patients: incidence, causative organisms and outcome. Clin Microbiol Infect 2013;19(2):187-192.

21. Niederman MS, Mandell LA, Anzueto A, Barlett JG, Campbell GD, Dean NC, et al; American Thoracic Society. Guidelines for the management of adults with community-acquired pneumonia. Diagnosis, assessment of severity, antimicrobial therapy and prevention. Am J Respir Crit Care Med 2001;163(7):1730-1754.

22. Magiorakos AP, Srinivasan A, Carey RB, Carmeli Y, Falagas ME, Giske CG, et al. Multidrug-resistant, extensively drug-resistant and pandrug-resistant bacteria: an international expert proposal for interim standard definitions for acquired resistance. Clin Microbiol Infect 2012;18(3):268-281.

23. Fine MJ, Auble TE, Yealey DM, Hanusa BH, Weissfeld LA, Singer $\mathrm{DE}$ et al. A prediction rule to identify low-risk patients with community-acquired pneumonia. N Engl J Med 1997;336(4):243-250.

24. Lim WS, Lewis S, Macfarlane JT. Severity prediction rules in community-acquired pneumonia: a validation study. Thorax 2000;55(3): 219-223.

25. Restrepo MI, Mortensen EM, Anzueto A. Are COPD patients with pneumonia who are taking inhaled corticosteroids at higher risk of dying? Eur Respir J 2011;38(1):1-3.
26. Crim C, Calverley PMA, Anderson JA, Celli B, Fergusson GT, Jenkins C. Pneumonia risk in COPD patients receiving inhaled inhaled corticoesteroids alone or in combination: TORCH study result. Eur Respir J 2009;34(3):641-647.

27. Singanayagam A, Chalmers JD, Hill AT. Inhaled corticoesteroids and risk of pneumonia: evidence for and against the proposed association. QJM 2010;103:379-385.

28. Sethi S, Murphy TF. Infection in the pathogenesis and course of chronic obstructive pulmonary disease. N Engl J Med 2008;359(22): 2355-2365.

29. Martinez R, Reyes S, Menendez R. Pulmonary nocardiosis: risk factors, clinical features, diagnosis and prognosis. Curr Opin Pulm Med 2008;14(3):219-227.

30. Liapikou A, Polverino E, Ewig S, Cilloniz C, Marcos MA, Mensa J, et al. Severity and outcomes of hospitalized community-acquired pneumonia in COPD patients. Eur Respir J 2012;39(4):855-861.

31. Marin A, Monso E, Garcia-Nunez M, Sauleda J, Nogjera A, Pons J, et al. Variability and effects of bronchial colonization in patients with moderate COPD. EurRespir J 2010;35(2):295-302.

32. Costelloe C, Metcalfe C, Lovering A, Mant D, Hay AD. Effect of antibiotic prescribing in primary care on antimicrobial resistance in individual patients: systematic review and meta-analysis. BMJ 2010; 340:c2096. 